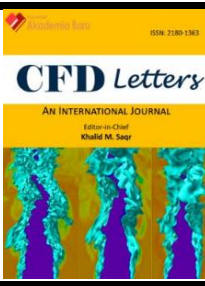

\title{
Validation Study of Photovoltaic Thermal Nanofluid Based Coolant Using Computational Fluid Dynamics Approach
}

\author{
Mohd Afzanizam Mohd Rosli ${ }^{1,2 *}$, Yew Wai Loon ${ }^{1}$, Muhammad Zaid Nawam ${ }^{1}$, Suhaimi Misha ${ }^{1,2}$, \\ Aiman Roslizar ${ }^{1}$, Faridah Hussain ${ }^{3}$, Nurfaizey Abdul Hamid ${ }^{1,2}$, Zainal Arifin ${ }^{4}$, Safarudin Gazali \\ Herawan $^{5}$ \\ Fakulti Kejuruteraan Mekanikal, Universiti Teknikal Malaysia Melaka, Hang Tuah Jaya, 76100, Durian Tunggal, Melaka, Malaysia \\ Centre for Advanced Research on Energy, Universiti Teknikal Malaysia Melaka, Hang Tuah Jaya, 76100, Durian Tunggal, Melaka, Malaysia \\ National Metrology Laboratory, SIRIM Berhad, 43900 Sepang, Selangor, Malaysia \\ Department of Mechanical Engineering, Sebelas Maret University, Jl. Ir. Sutami 36A, Surakarta, Indonesia \\ Industrial Engineering Department, Faculty of Engineering, Bina Nusantara University, Jakarta, Indonesia
}

\section{ARTICLE INFO $\quad$ ABSTRACT}

\section{Article history:}

Received 31 December 2020

Received in revised form 22 March 2021

Accepted 23 March 2021

Available online 31 March 2021
Keywords:

Photovoltaic thermal system (PVT);

Nanofluid coolant; CFD

\begin{abstract}
In the study, the photovoltaic thermal system using nanofluid as coolant is validated using numerical approach by comparing the experimental results and simulation results. Due to high cost and difficulty in preparing nanofluid, it is more practical to perform the study using numerical approach which is convenient and saves plenty of time. The photovoltaic thermal system is investigated numerically through Computational Fluid Dynamics Approach using Ansys 19.0 Fluent Software. The numerical study is based on different solar irradiation at different hours. The coolant that is selected in the study is aluminum oxide $\left(\mathrm{Al}_{2} \mathrm{O}_{3}\right)$ water nanofluid. The validation study between the experimental results and simulation results are achieved by examining the photovoltaic (PV) surface temperature and nanofluid outlet temperature. The maximum percentage of error between experimental and simulation results of PV surface temperature and nanofluid outlet temperature are $12.66 \%$ and $7.89 \%$. Also, the mean average percentage error (MAPE) are computed for PV surface temperature and nanofluid outlet temperature. The results for PV surface temperature and nanofluid outlet temperature are $10.31 \%$ and $6.67 \%$. Since the MAPE results are within $10 \%$ or error, it proved that there are good accuracy between the simulation and experimental results.
\end{abstract}

\section{Introduction}

Today, energy become increasingly important owing to growing of human population around the world. Energy is essential for development of economic, social and a better life [1]. The main energy resources in the modern world can be classified into different categories such as nuclear, fossil, and renewable. The energy resources are the source of fuels that contribute to generation of electrical energy and other form of human activities such as heating [2].

\footnotetext{
* Corresponding author.

E-mail address: afzanizam@utem.edu.my (Mohd Afzanizam Mohd Rosli)
} 
According to Global Energy Statistical Yearbook of 2020, the global energy consumption increases in an average rate of $2 \%$ from year 2000 - 2018 [3]. The growing demand of energy consumption, specifically electricity, has encouraged the International Energy Agency to search for alternative energy resources. The most significant matters that concerned by the entire globe currently is the depletion of fossil fuels which is the major resources used for electricity generation.

Solar energy conversion technologies have been studied by researcher over the past decades. It has become well established and exhibits potential compared to other sustainable energy. The solar energy can be harnessed using different technologies such as photovoltaic, photothermal, and photovoltaic thermal system. The distinctive features of photovoltaic thermal system over conventional solar system is the generation of electricity and heat energy simultaneously.

The electrical efficiency of the photovoltaic thermal (PVT) system is affected by the temperature of PV module. The heat energy that is trapped on the surface of PV module will result in drop of efficiency [4]. The unwanted heat energy should be removed from the PV surface so that the PV module meet its design efficiency. One of the methods to remove the heat energy from the photovoltaic thermal (PVT) system is the use of absorber tube to extract the excessive heat generated.

There are numerous studies focused on photovoltaic thermal (PVT) system by different researchers to study its performance. In an experimental study, Sardarabadi et al., [5] has investigated the electrical performance of PV and PVT system. The experimental results revealed that the electrical performance of PVT system is better than PV system because the excess heat is removed to enhance the electrical performance of the system.

In another experimental study, Goh Li Jin et al., [6] has investigated on water based photovoltaic thermal collector (PVT) to determine its effectiveness on improving photovoltaic cell efficiency. A spiral flow absorber tube is equipped to the PV system to facilitate heat transfer between PV system and absorber tube. The PVT system has showed an improvement of $65 \%$ overall efficiency and $12 \%$ electrical efficiency compared to PV system when water is used as coolant.

In addition, Slimani et al., [7] has investigated the energy performance of hybrid photovoltaic thermal solar collector. The PVT system has been equipped with double-pass air flow passage. The results showed that the double-pass air flow passage is favourable to improve the heat exchange between the collector. The higher heat exchange rate allows more heat absorbed by the air to improve the thermal efficiency and overall efficiency of the collector.

Most of the experimental studies that have been done previously are focused on using water and air as working fluid to extract the excessive heat generated. Recently, some of the researchers have started to utilise nanofluid as working fluid in solar system $[8,9]$. They investigated the influence of nanofluid in enhancing heat transfer in the system. The study results showed that addition of small amount of nanoparticles has significant effect in heat transfer enhancement [10].

In an experimental study, Sardarabadi et al., [5] has investigated deionised water, aluminium oxide nanofluid, titanium oxide nanofluid, and zinc oxide nanofluid in photovoltaic thermal system. Among different type of coolant used, zinc oxide has better thermal performance and higher electrical efficiency. Hence, it is evident that nanofluid performs better to enhance the system efficiency compared to conventional fluid such as water.

In a numerical study, Khanjari et al., [11] has performed investigation on using nanofluid in a water-cooled photovoltaic thermal system. The numerical study has the energy and exergy efficiency of the system. The study suggested that nanoparticles has enhanced the thermo-physical properties working properties compared to pure water. The enhancement will provide greater effect on heat transfer performance.

In summary, most of the previous numerical studies were focused on solving the energy balance equations. Computational Fluid Dynamics approach is seldom used by researchers in the study of PVT 
system. Due to complicated step and high cost in preparation of nanofluid, it is suggested to use numerical approach to predict the performance of PVT system. The objective of the study is to validate the simulation results with experimental results using nanofluid as coolant in PVT system.

\section{Methodology}

\subsection{Geometry Modelling}

The geometry of photovoltaic thermal (PVT) system is developed using SolidWorks 2018 software based on the actual geometry of photovoltaic thermal (PVT) system used by other researcher in their experiment study [12]. The schematic diagram of the photovoltaic thermal system is displayed in the Figure 1. As shown, the geometry model of photovoltaic thermal (PVT) system has different layers which include glass, PV cell, absorber plate, adhesive, absorber tube, and working fluid. The dimension of the geometry model is displayed in the Table 1.

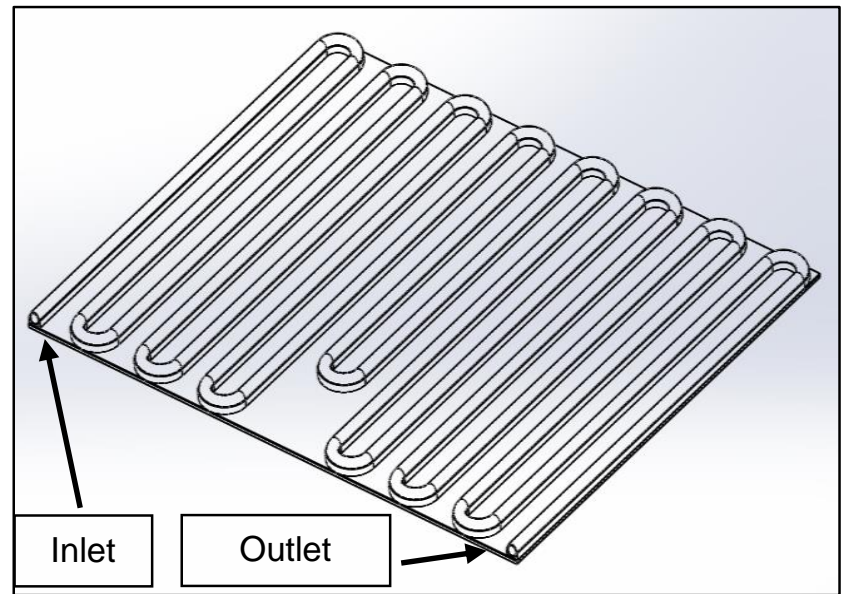

(a) Serpentine absorber tube

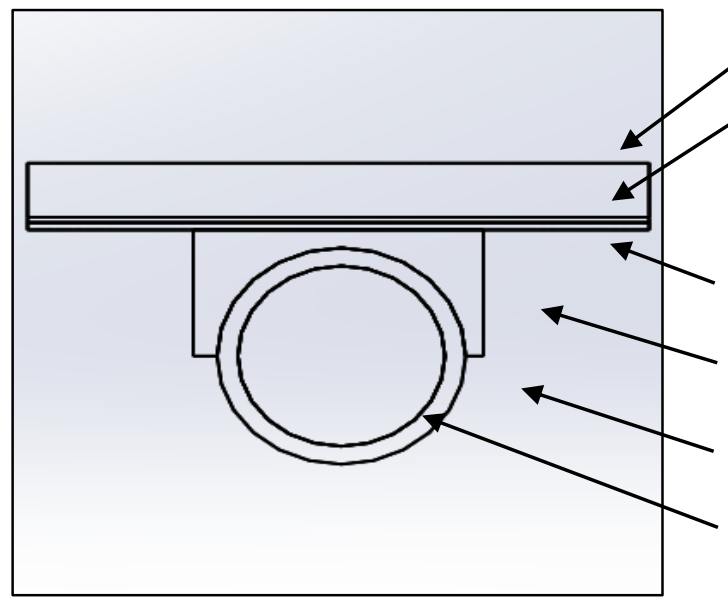

(b) Detail of serpentine absorber tube

Glass

PV Cell

Absorber

Plate

Adhesive

Absorber

Tube

Working

Fluid

Fig. 1. Configuration of photovoltaic thermal (PVT) system

Table 1

Geometry size of photovoltaic thermal (PVT) system

\begin{tabular}{ll}
\hline Component & Dimension $(\mathrm{mm})$ \\
\hline Glass & $630 \times 540 \times 3$ \\
PV cell & $630 \times 540 \times 0.3$ \\
Absorber plate & $630 \times 540 \times 0.4$ \\
Adhesive & $14 \times 7$ \\
Absorber tube & Inner diameter: 10 \\
& Outer diameter: 12 \\
\hline
\end{tabular}

\subsection{Mesh Study}

The geometry of the photovoltaic thermal (PVT) system is meshed in Ansys 2019 ICEM software. Meshing is an important stage before engineering simulation to divide the complex geometries into more simple elements to use as local approximation. If the meshing produces too much cells, the computational time will become longer and not cost efficient. If the meshing produces too little cells, the simulation results will become inaccurate for the study [13]. Therefore, the meshing method is significant and will affect the accuracy, convergence, and speed of simulation.

3D structured grid is employed near the walls of working fluid as presented in Figure 2. Structured grid is useful to lower the number of nodes and elements and reduce the computational time. Also, 
structured grids are aligned in flow direction and produce more accurate and better convergence in simulation software [14]. To mesh in structure gird, an O-grid blocking strategy is created within the cylindrical geometry. The O-grid blocking strategy is useful to fix bad angles in the block corners within the cylindrical geometry. The pre-specified pattern of the mesh is then generated as presented in Figure 2.

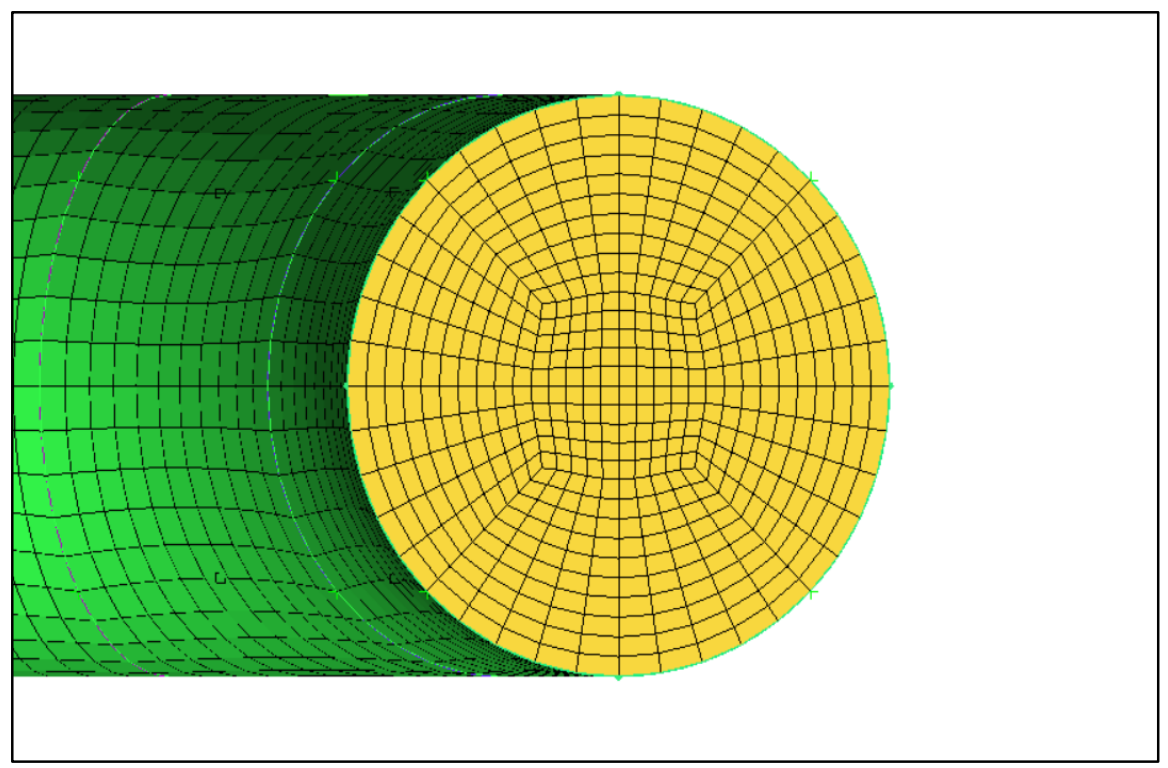

Fig. 2. Meshing of working fluid

A mesh independency test is performed to determine the dependence on the simulation results on the mesh density. For this purpose, the mesh sizing of the geometry model is further refined to produce much more cells. In other words, the mesh count of the geometry model is further increased to establish mesh independence. The results of average PV surface temperature and average outlet temperature are examined for various mesh sizes. The mesh system number 4 that is presented in Table 2 is selected for the present study as further refine in mesh does not have considerable effect on the study.

\section{Table 2}

\begin{tabular}{lllll}
\multicolumn{5}{l}{ Mesh independence study for experiment data $(10: 00$ am) } \\
\hline Mesh system & Number of nodes & Number of elements & PV temperature $\left({ }^{\circ} \mathrm{C}\right)$ & Outlet temperature $\left({ }^{\circ} \mathrm{C}\right)$ \\
\hline 1 & 467715 & 261005 & 40.85 & 39.28 \\
2 & 656072 & 466971 & 40.90 & 39.38 \\
3 & 1028413 & 624154 & 40.98 & 39.42 \\
4 & 2196264 & 1416540 & 41.05 & 39.45 \\
5 & 5410671 & 3757090 & 41.10 & 39.52 \\
\hline
\end{tabular}

\subsection{Numerical Procedure}

\subsubsection{Fluid flow characteristics and simulation assumptions}

The fluid flow inside the absorber tube is laminar which is found in experimental studies $[5,12]$. Based on the Reynolds number, it helps to predict the fluid flow patterns whether they are in laminar or turbulent regime. The formula to calculate the Reynolds Number is presented in the Eq. (1). The calculated Reynolds number for a mass flow rate of $40 \mathrm{~kg} / \mathrm{h}$ is 2290 . The critical Reynolds number for fluid flow is 2300. If the fluid flow Reynolds number is greater than the critical Reynolds number, it is classified as turbulent flow or otherwise. The mass flow rate of the fluid in the experimental study is 
set at constant mass flow rate of $30 \mathrm{~kg} / \mathrm{h}$. Therefore, the flow regime in the absorber tube is considered to be laminar flow.

$R e=\frac{\rho v d}{\mu}=\frac{4 \dot{Q}}{\pi d \mu}$

In simulation, the mass flow rate of the working fluid is $30 \mathrm{~kg} / \mathrm{h}$ for all the case study. Based on the Eq. (1), the Reynolds number is calculated in order to determine the working fluid flow regime. The calculated Reynolds number for a mass flow rate of $30 \mathrm{~kg} / \mathrm{h}$ is 1720 . Hence, the flow regime of the working fluid is classified as laminar flow because the Reynolds number is less than the critical Reynolds number which is 2300 . Also, the geometry model of the photovoltaic thermal (PVT) system is developed based on the actual dimension. Therefore, the geometry model used is 1 to 1 scale and the Reynolds number remains the same due to actual size.

In addition, the heat transfer coefficient is proportional to Nusselt number and thermal conductivity, where Nusselt number is related to Reynolds and Prandtl number of nanofluid. The Reynolds number has an inverse relationship with the viscosity where it reduces with increasing nanoparticles concentration. Prandtl number has a direct relationship with the viscosity while inverse relationship with the thermal conductivity. Therefore, the effect of adding nanoparticles on Nusselt number is determined by reduction of Reynolds number and enhancement of Prandtl number.

In laminar flow, the effects of Prandtl number is dominant compared to Reynolds number. In turbulent flow, the effects of Reynolds number is dominant compared to Prandtl number. Due to the behaviour of heat transfer coefficient, when increasing the volume fraction of nanoparticles, the PV temperature reduces in laminar flow regime, while increases in turbulent flow regime. Therefore, the nanofluid performs better in laminar flow compared to turbulent flow in the photovoltaic thermal (PVT) system. The numerical simulation of PVT system is based on the following assumptions

i. The fluid is in steady state, incompressible and uniform.

ii. The fluid has constant mass flow rate with laminar flow.

iii. Solar radiation is perpendicular to the surface of geometry.

iv. Radiation heat loss and reflection of sunlight is negligible to simplify calculation [11].

v. There is perfect contact between various components in the photovoltaic thermal (PVT) system. Therefore, the temperature predicted for the PV and absorber plate are almost the same [11].

vi. The thermophysical properties of the components in the photovoltaic thermal (PVT) system are assumed constant $[12,15]$.

vii. The bottom of the absorber plate, absorber tube, and side walls of the photovoltaic thermal (PVT) system are considered adiabatic walls [15].

viii. The nanofluid used in the simulation is assumed as single-phase fluid in which the base fluid and nanoparticles are in thermal equilibrium state.

\subsubsection{Governing equations}

Pressure-based finite volume method is used to discretise the continuous governing equations into algebraic equations. The algebraic equations are then solved numerically to obtain the solution field. Different convergence criteria are set to produce the velocity and temperature field solutions. The convergence criteria for continuity, momentum, and energy equation are achieved when the residuals of the solution drop to $10^{-3}, 10^{-3}, 10^{-6}$ respectively. To evaluate the heat transfer between the solid-fluid interface, a 'coupled' wall is applied in the wall boundary condition to allow conjugate 
heat transfer to occur. For the purpose, the geometry model is divided into two domains which is glass, PV cell, absorber plate, adhesive, absorber tube as solid domain, while the working fluid as fluid domain. The viscous laminar model is selected to solve and analyse the laminar flow in the absorber tube.

From the above assumptions, the fluid flow in the photovoltaic thermal (PVT) system is steady and incompressible. If the PVT system is treated as a control volume, the governing equations of continuity, momentum, and flow energy are shown below

Continuity equation: $\quad \nabla \cdot\left(\rho_{\mathrm{nf}} \vec{V}_{\mathrm{nf}}\right)=0$

Momentum equation: $\quad \nabla \cdot\left(\rho_{\mathrm{nf}} \vec{V}_{\mathrm{nf}} \vec{V}_{\mathrm{nf}}\right)=-\nabla P+\nabla\left(\mu_{\mathrm{nf}} \nabla \vec{V}_{\mathrm{nf}}\right)$

Flow energy equation: $\quad \nabla \cdot\left(\vec{V}_{\mathrm{nf}} \rho_{\mathrm{nf}} C_{\mathrm{p}, \mathrm{nf}} T_{\mathrm{nf}}\right)=-\nabla P+\nabla\left(k_{\mathrm{nf}} \nabla T_{\mathrm{nf}}\right)$

In the equation above, $\vec{V}_{\mathrm{nf}}, P, \rho_{\mathrm{nf}}, \mu_{\mathrm{nf}}, C_{\mathrm{p}, \mathrm{nf}}, T_{\mathrm{nf}}, k_{\mathrm{nf}}$ are fluid velocity, pressure, density, shear stress, specific heat capacity, temperature, and thermal conductivity. The subscript nf refers to the nanofluid used in the study.

\subsubsection{Thermophysical properties of nanofluid}

Density of nanofluid

$\rho_{\mathrm{nf}}=\emptyset \cdot \rho_{\mathrm{np}}+(1-\emptyset) \cdot \rho_{\mathrm{bf}}$

In the equation above, $\rho_{\mathrm{nf}}, \rho_{\mathrm{np}}, \rho_{\mathrm{bf}}, \emptyset$ are nanofluid density, nanoparticle density, base fluid density, and nanoparticle concentration.

Specific heat capacity

$C_{\mathrm{p}, \mathrm{nf}}=\frac{\emptyset \cdot\left(\rho_{\mathrm{np}} C_{\mathrm{p}, \mathrm{np}}\right)+(1-\emptyset) \cdot\left(\rho_{\mathrm{bf}} C_{\mathrm{p}, \mathrm{bf}}\right)}{\rho_{\mathrm{nf}}}$

In the equation above, $\rho_{\mathrm{nf}}, \rho_{\mathrm{np}}, \rho_{\mathrm{bf}}, C_{\mathrm{p}, \mathrm{np}}, C_{\mathrm{p}, \mathrm{nf}}, C_{\mathrm{p}, \mathrm{bf}}, \emptyset$ are nanofluid density, nanoparticle density, base fluid density, nanoparticle specific heat capacity, nanofluid specific heat capacity, base fluid specific heat capacity and nanoparticle concentration.

Thermal conductivity

$k_{\mathrm{nf}}=\frac{\left(k_{\mathrm{np}}+2 k_{\mathrm{bf}}\right)+2 \varnothing\left(k_{\mathrm{np}}-k_{\mathrm{bf}}\right)}{\left(k_{\mathrm{np}}+2 k_{\mathrm{bf}}\right)-\emptyset\left(k_{\mathrm{np}}-k_{\mathrm{bf}}\right)} \cdot k_{\mathrm{bf}}$

In the equation above, $k_{\mathrm{nf}}, k_{\mathrm{np}}, k_{\mathrm{bf}}, \emptyset$ are nanofluid specific heat capacity, nanoparticle specific heat capacity, base fluid specific heat capacity and nanoparticle concentration.

Viscosity 
$\mu_{\mathrm{nf}}=\frac{\mu_{\mathrm{bf}}}{1-34.87\left(\frac{d_{\mathrm{np}}}{d_{\mathrm{bf}}}\right)^{-0.3} \emptyset^{1.03}}$

In the equation above, $\mu_{\mathrm{nf}}, \mu_{\mathrm{bf}}, d_{\mathrm{np}}, d_{\mathrm{bf}}, \emptyset$ are viscosity of nanofluid, viscosity of base fluid, diameter of nanoparticle, diameter of base fluid, and concentration of nanoparticle.

\subsubsection{Performance of photovoltaic thermal (PVT) system}

Electrical energy efficiency

$\eta_{\mathrm{el}}=\eta_{\mathrm{r}}\left[\left(1-\beta_{\mathrm{r}}\right)\left(T_{\mathrm{pv}}-T_{\mathrm{r}}\right)\right]$

The equation above is used to estimate the electrical energy efficiency of the PVT system by using the empirical relationship in which $\eta_{\mathrm{pv}}, \eta_{\mathrm{r}}, \beta_{\mathrm{r}}, T_{\mathrm{pv}}, T_{\mathrm{r}}$ are electrical energy efficiency, PV module efficiency, beta coefficient under standard test condition (STC), PV cell temperature, and reference temperature under standard test condition (STC).

Thermal energy efficiency

$\eta_{\mathrm{th}}=\frac{\dot{m}_{\mathrm{nf}} c_{\mathrm{p}, \mathrm{nf}}\left(T_{\mathrm{nf}, \mathrm{out}}-T_{\mathrm{nf}, \mathrm{in}}\right)}{I A_{\mathrm{c}} \tau_{\mathrm{g}} \alpha_{\mathrm{pv}}}$

The equation above is used to estimate the thermal energy efficiency of the PVT system by using the empirical relationship in which $\eta_{\mathrm{th}}, \dot{m}_{\mathrm{nf}}, c_{\mathrm{p}, \mathrm{nf}}, T_{\mathrm{nf}, \text { out }}, T_{\mathrm{nf}, \mathrm{in}}, I, A_{\mathrm{c}}, \tau_{\mathrm{g}}, \alpha_{\mathrm{pv}}$ are thermal energy efficiency, nanofluid mass flow rate, nanofluid specific heat capacity, nanofluid outlet temperature, nanofluid inlet temperature, solar irradiation, cross-sectional area of collector, transmissivity of glass, and absorptivity of PV cell.

Overall energy efficiencies

$\eta_{\mathrm{ov}}=\eta_{\mathrm{el}}+\eta_{\mathrm{th}}$

The equation above is used to calculate the overall energy efficiencies of the PVT system considering both electrical and thermal energy efficiency.

\subsubsection{Numerical setup}

The performance of nanofluid photovoltaic thermal (PVT)) system is numerically investigated using Computational Fluid Dynamics (CFD) approach. In fact, the numerical simulation is conducted using Ansys Fluent 2019 R3 software. The numerical simulation of the photovoltaic thermal (PVT) system is achieved through solving the three main conservative laws (conservation of mass, momentum, and energy) for the fluid flow.

The material properties for different components in the photovoltaic thermal (PVT) system is presented in the Table 3. The schematic diagram of the numerical setup is presented in the Figure 1. In numerical simulation, the solar radiation that falls on the glass and PV panel is modelled directly using heat flux [16]. This is because solar load model does not account for heat gains for opaque surface [17]. The heat flux applied to the wall boundary condition is corresponded to the solar 
radiation absorbed by the body. The absorptivity of glass is 0.1 so the heat flux is $10 \%$ of the solar radiation at the time. The transmissivity of glass is 0.95 while the absorptivity of PV is 0.9 . The product of these two values is 0.85 so the heat flux is $85 \%$ of solar irradiation.

The boundary condition for different components in the photovoltaic thermal (PVT) system is presented in the Table 4. The top part of the glass is subjected to free convection from wind and the convection coefficient is calculated based on the equation Eq. (12)-(13). The ambient temperature is the environment temperature that is taken from the experiment. Heat source is applied at the top of glass and PV according to the absorptivity and thickness of the part. Other part of geometry such as PV, absorber and tube are coupled to allow conjugate heat transfer [11]. The conjugate heat transfer allows the heat conduction and convection between various components in the photovoltaic thermal (PVT) system. The fluid inlet temperature is also specified and is taken from the experiment.

$$
\begin{aligned}
& \mathrm{h}_{\mathrm{g}-\mathrm{a}}=5.7+3.8 \mathrm{v}_{\mathrm{w}}, \mathrm{v}_{\mathrm{w}}<5 \mathrm{~m} / \mathrm{s} \\
& \mathrm{h}_{\mathrm{g}-\mathrm{a}}=6.47+\mathrm{v}_{\mathrm{w}}{ }^{0.78}, \mathrm{v}_{\mathrm{w}}>5 \mathrm{~m} / \mathrm{s}
\end{aligned}
$$

Table 3

\begin{tabular}{|c|c|c|c|c|}
\hline Component & Parameter & Value & Unit & References \\
\hline \multirow[t]{3}{*}{ Glass cover } & Density & 2400 & $\mathrm{~kg} / \mathrm{m}^{3}$ & Filipović et al., [16] \\
\hline & Thermal conductivity & 700 & $\mathrm{~W} / \mathrm{mK}$ & Filipović et al., [16] \\
\hline & Specific heat capacity & 1.3 & $\mathrm{~J} / \mathrm{kgK}$ & Filipović et al., [16] \\
\hline \multirow[t]{6}{*}{ PV panel } & Density & 2330 & $\mathrm{~kg} / \mathrm{m}^{3}$ & Hosseinzadeh et al., [12] \\
\hline & Thermal conductivity & 749 & $\mathrm{~W} / \mathrm{mK}$ & Hosseinzadeh et al., [12] \\
\hline & Specific heat capacity & 148 & $\mathrm{~J} / \mathrm{kgK}$ & Hosseinzadeh et al., [12] \\
\hline & Reference temperature coefficient & 0.0045 & $\mathrm{~K}^{-1}$ & Hosseinzadeh et al., [12] \\
\hline & Reference temperature & 298 & $\mathrm{~K}$ & Hosseinzadeh et al., [12] \\
\hline & Reference cell efficiency & 0.713 & - & Hosseinzadeh et al., [12] \\
\hline \multirow[t]{3}{*}{ Absorber plate } & Density & 8960 & $\mathrm{~kg} / \mathrm{m}^{3}$ & Hosseinzadeh et al., [12] \\
\hline & Thermal conductivity & 385 & $\mathrm{~W} / \mathrm{mK}$ & Hosseinzadeh et al., [12] \\
\hline & Specific heat capacity & 401 & $\mathrm{~J} / \mathrm{kgK}$ & Hosseinzadeh et al., [12] \\
\hline \multirow[t]{3}{*}{ Tube } & Density & 8960 & $\mathrm{~kg} / \mathrm{m}^{3}$ & Hosseinzadeh et al., [12] \\
\hline & Thermal conductivity & 385 & $\mathrm{~W} / \mathrm{mK}$ & Hosseinzadeh et al., [12] \\
\hline & Specific heat capacity & 401 & $\mathrm{~J} / \mathrm{kgK}$ & Hosseinzadeh et al., [12] \\
\hline \multirow[t]{3}{*}{ Adhesive } & Density & 2500 & $\mathrm{~kg} / \mathrm{m}^{3}$ & Khanjari et al., [18] \\
\hline & Thermal conductivity & 650 & $\mathrm{~W} / \mathrm{mK}$ & Khanjari et al., [18] \\
\hline & Specific heat capacity & 0.88 & $\mathrm{~J} / \mathrm{kgK}$ & Hussain et al., [17] \\
\hline \multirow[t]{4}{*}{$\mathrm{Al}_{2} \mathrm{O}_{3}$ nanofluid } & Density & 1003.05 & $\mathrm{~kg} / \mathrm{m}^{3}$ & Hosseinzadeh et al., [12] \\
\hline & Thermal conductivity & 4151.98 & $\mathrm{~W} / \mathrm{mK}$ & Hosseinzadeh et al., [12] \\
\hline & Specific heat capacity & 0.6165 & $\mathrm{~J} / \mathrm{kgK}$ & Hosseinzadeh et al., [12] \\
\hline & Total mass flow rate in laminar & 0.0083 & $\mathrm{~kg} / \mathrm{s}$ & Hosseinzadeh et al., [12] \\
\hline \multirow[t]{3}{*}{ Operating conditions } & Wind velocity & 5 & $\mathrm{~m} / \mathrm{s}$ & Hosseinzadeh et al., [12] \\
\hline & Fluid inlet temperature & Table 5 & $\mathrm{~K}$ & Hosseinzadeh et al., [12] \\
\hline & Ambient temperature & Table 5 & $\mathrm{~K}$ & Hosseinzadeh et al., [12] \\
\hline
\end{tabular}

Material properties for different components in model

In the numerical simulation, 'mass flow inlet' is applied to the inlet for working fluid. The 'inlet' and 'outlet' temperature are specified according to the measurement from the experiment. For the outlet of working fluid, 'pressure outlet' boundary condition is chosen because the fluid is incompressible. Also, 'no slip' and 'impermeable' boundary condition are applied to the walls at boundary condition. The heat generation rate at the top of the glass and PV is based on the experiment data from Table 5. To employ the boundary condition, the surface heat flux is converted 
to volumetric heat flux. Bottom surface of absorber plate and external surface of tube are assumed adiabatic with no heat loss. Radiation heat transfer is not considered in the stud because the heat loss through radiation is neglected.

Table 4

Boundary condition for the model $(10: 00 \mathrm{am})$

\begin{tabular}{llll}
\hline Part & \multicolumn{2}{l}{ Thermal Boundary Condition } \\
& $\begin{array}{l}\text { Ambient/ Inlet } \\
\text { temperature }\left({ }^{\circ} \mathrm{C}\right)\end{array}$ & Convective heat transfer coefficient $\left(\mathrm{W} / \mathrm{m}^{2} \mathrm{~K}\right)$ & $\begin{array}{l}\text { Heat source } \\
\left(\mathrm{W} / \mathrm{m}^{3}\right)\end{array}$ \\
\hline glass top & 30.8 & 24.7 & 24000 \\
PV top & coupled & - & 2040000 \\
absorber top & coupled & - & - \\
adhesive & coupled & - & - \\
absorber tube & coupled & - & - \\
fluid & 35.0 & - & - \\
\hline
\end{tabular}

Table 5

Solar irradiation experiment data

\begin{tabular}{llll}
\hline Time (Hours) & Solar Irradiation $\left(\mathrm{W} / \mathrm{m}^{2}\right)$ & Ambient Temperature $\left({ }^{\circ} \mathrm{C}\right)$ & Fluid Inlet Temperature $\left({ }^{\circ} \mathrm{C}\right)$ \\
\hline 10:00 am & 720 & 30.8 & 34.5 \\
$11: 00 \mathrm{am}$ & 910 & 32.4 & 40.0 \\
$12: 00 \mathrm{pm}$ & 1020 & 33.6 & 41.0 \\
1:00 pm & 1040 & 34.4 & 43.5 \\
2:00 pm & 1000 & 35.2 & 43.5 \\
3:00 pm & 860 & 36.4 & 43.0 \\
\hline
\end{tabular}

\subsubsection{Numerical scheme}

Since the working fluid is incompressible, pressure-based solver is selected for the simulation. Laminar model is selected as the model according to the experiment of PV/T. For turbulent regime, the turbulent model which is k-epsilon model is widely used. SIMPLE (Semi Implicit Method for Pressure-Linked Equations) scheme is widely used previously by researcher to determine pressure and velocity field and is selected as the scheme to be applied in simulation.

The upwind scheme is selected as second order upwind for pressure, momentum, and energy equation. The gradient used to discretize the flow conservation equations is least squared cell based [11].The double precision is selected to solve the problem to achieve more accurate results. The convergence residuals are maintained as default value and the iteration will stop once the residual value of energy, continuity, and energy fall to the prescribe default value.

\section{Verification and Validation}

The verification and validation of the numerical model of photovoltaic thermal (PVT) system is compared to the experiment study [5]. The simulation is conducted in the software using 3dimensional steady state approach to predict the average PV surface temperature and the working fluid outlet temperature. The required input parameters to perform the simulation includes solar irradiation at different hours, ambient temperature, working fluid mass flow rate, working fluid inlet temperature, and wind velocity. The verification and validation work are completed by comparing the experimental results and numerical results. 


\section{Results and Discussion}

The experimental and simulation results are presented in the Figure 3 and Figure 4 . As observed, the average PV surface temperature for simulation results are lower compared to the experimental results for all the cases. The percentage of error range from a minimum of $8.45 \%$ to a maximum of $12.66 \%$. As observed, the average fluid outlet temperature for simulation results are higher compared to the experimental results for all the cases. The percentage of error range from a minimum of $4.71 \%$ to a maximum of $7.89 \%$. Hence, the validation results suggested that there is discrepancy when comparing both results.

In addition, the mean average percentage error (MAPE) is calculated to determine the accuracy of the simulation results with experimental results. The mean average percentage error (MAPE) is calculated by taking the sum of all errors divide by the number of observations in the study. The MAPE for the PV surface temperature and fluid outlet temperature are $10.31 \%$ and $6.67 \%$. Since the MAPE is within $10 \%$ percentage of error, it showed that there is good agreement between the simulation results and experimental results. The previous study conducted by Khanjari et al., and Suhaimi et al., have used the similar approach to determine accuracy of the validation results $[18,19]$.

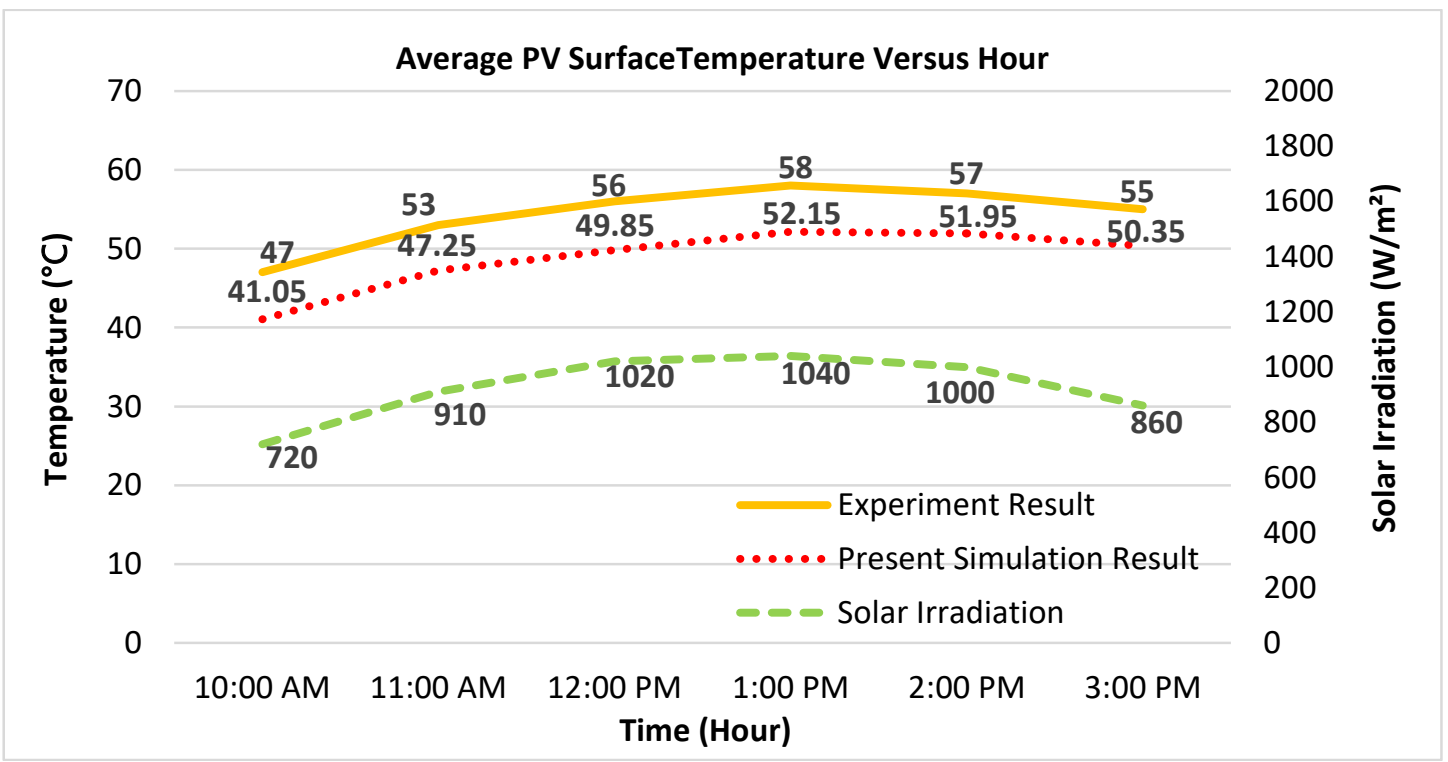

Fig. 3. Validation of PV temperature with experiment and simulation results

The reason for the PV surface temperature to be lower than the experimental values is due to the assumption of perfect contact between various components in the system. In fact, previous simulation study has also suggested that the condition is due to high heat transfer occurred between the absorber tube compared to actual condition [20]. Hence, it is evident that the simulated average PV surface temperature are lower compared to the experimental results. This is because all the heat in the PV has been absorbed by the working fluid that in contact with the copper tube.

The discrepancy of the outlet temperature of working fluid is due to the reason that there is much heat absorbed by the working fluid. In simulation study, the working fluid absorbed most of the heat which caused the outlet temperature to become significantly higher when compared to the experimental results. The increase in heat absorption causes the temperature of the working fluid to increase compared to the actual condition. In the experiment, it can be noticed that the outlet temperature is lower. However, the discrepancy is less than $10 \%$ which is still within the agreement and the possible reason is due to the uncertainty of the properties of thermal adhesive. 
Figure 5 shows the PV surface temperature distribution in present simulation compared to previous simulation study. The comparison of temperature contour between previous and present simulation show good agreement with each other. There are different highlighted regions in the temperature contour. The entrance region indicates the inlet section of working fluid across the copper tube. The exit region indicates the outlet section of the working fluid across the copper tube. The junction box is a rectangular box that acts as the housing of the electrical connections which is attached at the backside of the photovoltaic thermal (PVT) system.

In entrance region, the nanofluid just entered the photovoltaic thermal (PVT) system. It has absorbed most of the heat from the system because the fluid inlet temperature is significantly lower compared to the system. Therefore, much of the heat can be absorbed by the working fluid. As the working fluid flow across the copper tube, it will absorb the remaining heat from the system. However, the heat absorb ability of the working fluid is dropped when its temperature is increased. As a result, the working fluid only absorb a portion of the heat approaching the exit region. The temperature of the PVT become higher at the exit region.

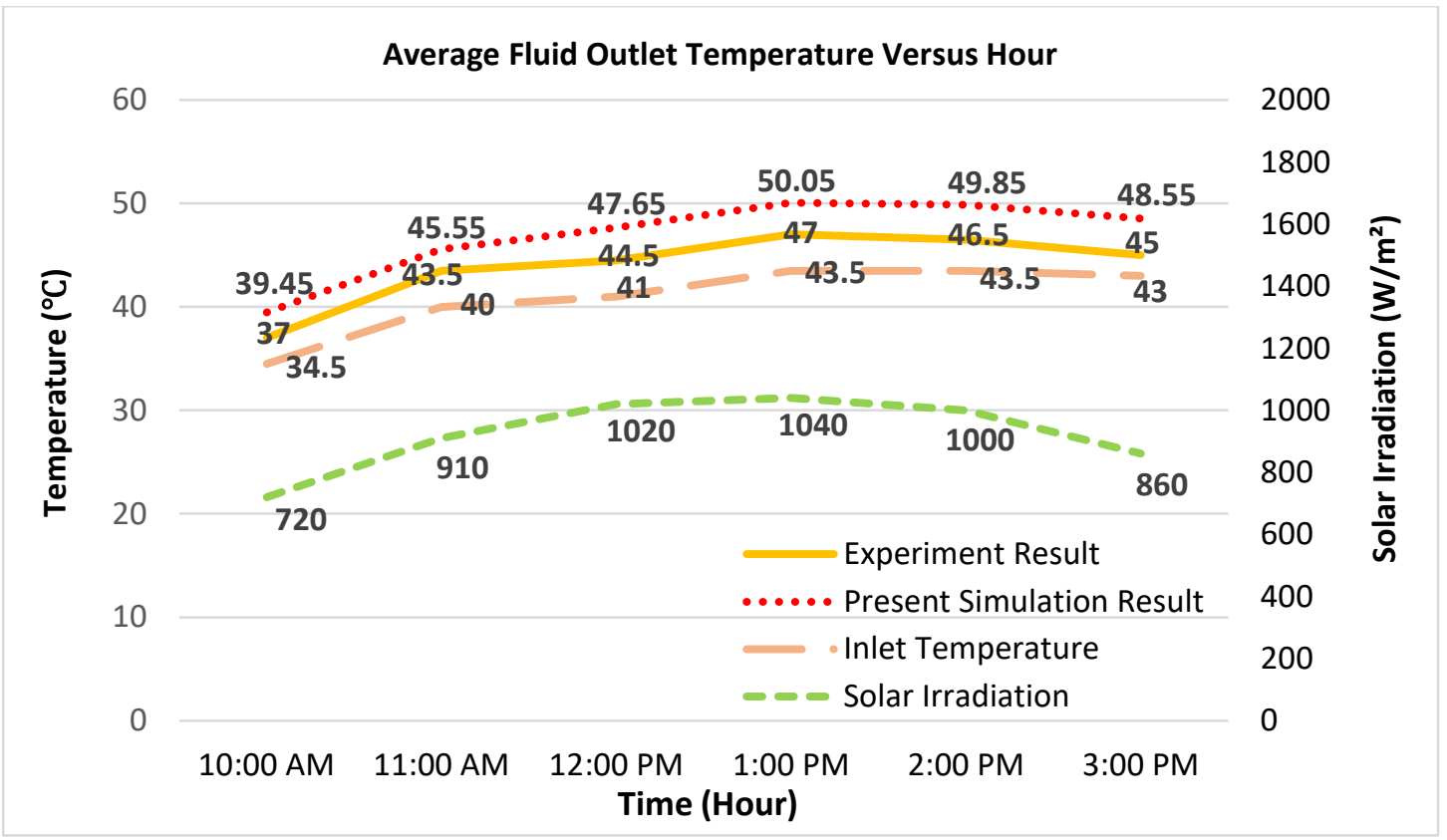

Fig. 4. Validation of fluid outlet temperature with experiment and simulation results

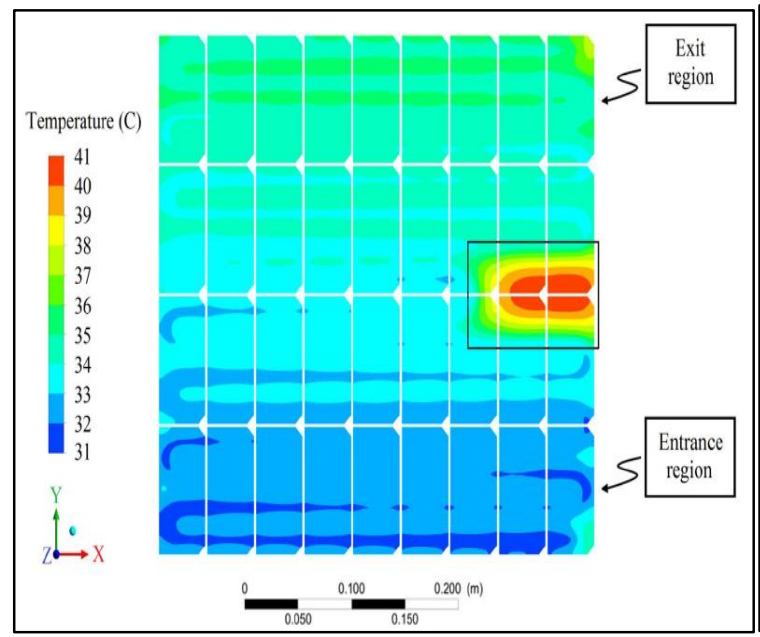

(a) Previous simulation result

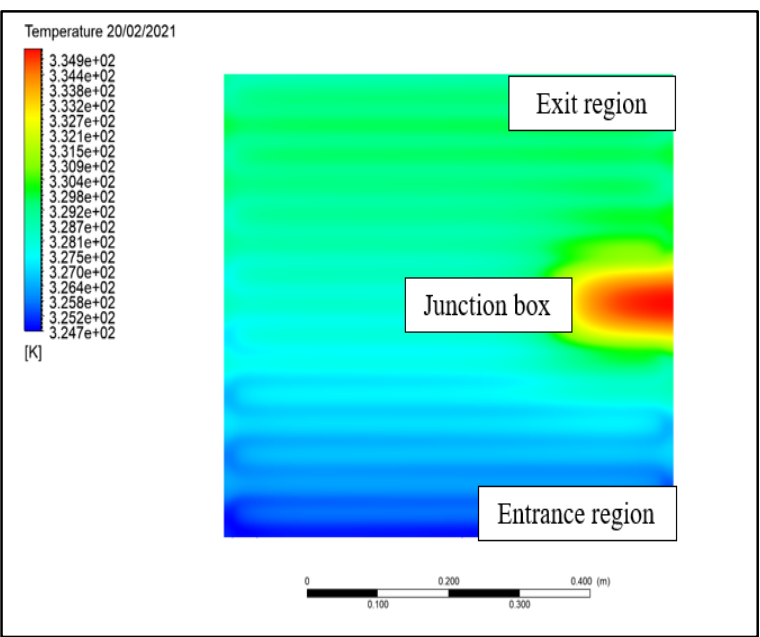

(b) Present simulation result

Fig. 5. PV surface temperature distribution between (a)journal and (b)author simulation results 
Figure 6 shows the fluid surface temperature distribution in present simulation compared to previous simulation study. The comparison of temperature distribution between previous and present simulation show good agreement with each other. There are different highlighted regions in the temperature distribution which include inlet region and outlet region. The inlet region is where the working fluid enters the collector pipe. The outlet region is where the working fluid leaves the collector pipe. There is a total of sixteen tubes for the serpentine tube configuration and the shorter length of the serpentine tube indicates the location of the junction box.

The inlet region has lowest temperature which is almost equal to the fluid inlet temperature. It is evident because the fluid just entered the collector pipe and only able to capture small portion of heat from the PVT system. Across the pipe, the collector pipe temperature is increased gradually when it flows through the other region of the PVT system. When the fluid approaches the outlet region, most of the heat of the PVT system has been absorbed by the fluid. Therefore, it can be observed that the outlet region has the highest temperature because the heat of the PVT system is accumulated at the outlet region.

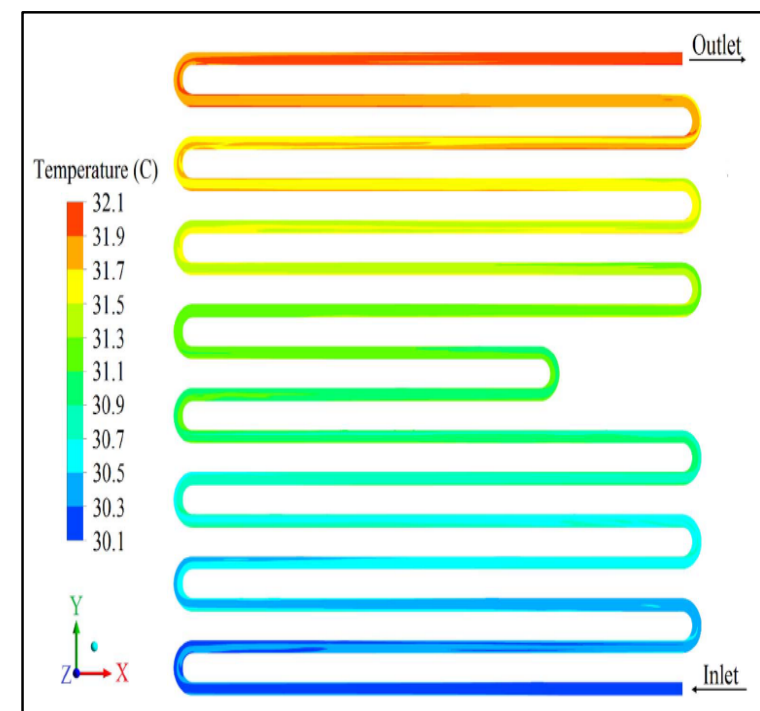

(a) Previous simulation result

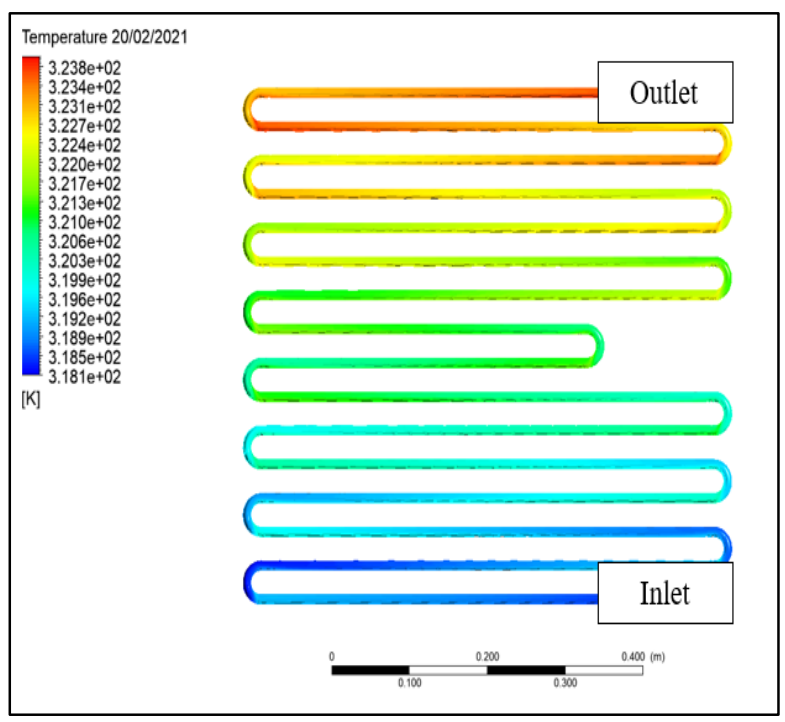

(b) Present simulation result

Fig. 6. Fluid surface temperature distribution between (a)journal and (b)author simulation results

\section{Conclusion}

In the present study, a simulation work is done to validate the numerical and experimental results of photovoltaic thermal (PVT) system using nanofluid as coolant. The present simulation work is compared to previous simulation work and experimental result from other study. The results indicate that the maximum percentage of error for the PV surface temperature and nanofluid outlet temperature are $12.66 \%$ and $7.89 \%$. Also, the mean average percentage error (MAPE) is calculated to determine the accuracy of the validation results. The results indicate that the MAPE for the PV surface temperature and nanofluid outlet temperature are $10.31 \%$ and $6.67 \%$. The MAPE is within $10 \%$ of error which proved that there is good agreement between simulation results and experimental results. Considering the assumption use in the simulation study, there appears some discrepancy between the experimental and simulation results. However, the results are still within the agreement after comparing with the other simulation study. In PV surface temperature distribution, the high temperature is concentrated in the junction box region. In fluid surface temperature distribution, the high temperature occurred at the exit region of the collector pipe. Both 
the journal and author simulation have obtained the same results. Hence, the calculated MAPE and temperature distribution of PV and fluid surface temperature distribution contour shows good agreement between present study and previous study which validates the work.

\section{Acknowledgement}

The authors would like to thank Applied Solar Energy Laboratory, Fakulti Kejuruteraan Mekanikal, and Universiti Teknikal Malaysia Melaka for the contributions and supports. This work was funded by the Malaysian Ministry of Higher Education under the grant FRGS/2018FKM-CARe/F00368.

\section{References}

[1] Acikgoz, Caglayan. "Renewable energy education in Turkey." Renewable Energy 36, no. 2 (2011): 608-611. https://doi.org/10.1016/i.renene.2010.08.015

[2] Novakovic, Bora, Adel Nasiri, and Muhammad H. Rashid. "Introduction to electrical energy systems." Electric renewable energy systems 1 (2015). https://doi.org/10.1016/B978-0-12-804448-3.00001-3

[3] Enerdata. "Total Energy Consumption." (2020).

[4] Razali, Nur Farhana Mohd, Ahmad Fudholi, Mohd Hafidz Ruslan, and Kamaruzzaman Sopian. "Electrical Characteristics of Photovoltaic Thermal Collector with Water-Titania Nanofluid Flow." Journal of Advanced Research in Fluid Mechanics and Thermal Sciences 73, no. 2 (2020): 20-28. https://doi.org/10.37934/arfmts.73.2.2028

[5] Sardarabadi, Mohammad, and Mohammad Passandideh-Fard. "Experimental and numerical study of metaloxides/water nanofluids as coolant in photovoltaic thermal systems (PVT)." Solar Energy Materials and Solar Cells 157 (2016): 533-542. https://doi.org/10.1016/i.solmat.2016.07.008

[6] Jin, G. O. H. L. I., Hafidz Ruslan, S. O. H. I. F. Mat, MOHD YUSOF Othman, Azami Zaharim, and Kamaruzzaman Sopian. "Experiment study on single-pass photovoltaic-thermal (PV/T) air collector with absorber." In 9th WSEAS International Conference on System Science and Simulation in Engineering, ICOSSSE, vol. 10, pp. 435-438. 2010.

[7] Slimani, Mohamed El Amine, Madjid Amirat, Sofiane Bahria, Ildikó Kurucz, and Rabah Sellami. "Study and modeling of energy performance of a hybrid photovoltaic/thermal solar collector: Configuration suitable for an indirect solar $\begin{array}{lllll}\text { dryer." Energy conversion } 209-221 . & \text { (2016): }\end{array}$ https://doi.org/10.1016/i.enconman.2016.03.059

[8] Mahian, Omid, Ali Kianifar, Soteris A. Kalogirou, loan Pop, and Somchai Wongwises. "A review of the applications of nanofluids in solar energy." International Journal of Heat and Mass Transfer 57, no. 2 (2013): 582-594. https://doi.org/10.1016/i.ijheatmasstransfer.2012.10.037

[9] Liu, Zhen-Hua, Ren-Lin Hu, Lin Lu, Feng Zhao, and Hong-shen Xiao. "Thermal performance of an open thermosyphon using nanofluid for evacuated tubular high temperature air solar collector." Energy Conversion and Management 73 (2013): 135-143. https://doi.org/10.1016/i.enconman.2013.04.010

[10] Fudholi, Ahmad, Nur Farhana Mohd Razali, Mohd Hafidz Ruslan, and Kamaruzzaman Sopian. "Application of Nanofluids for Photovoltaic Thermal (PVT) Collectors: A Review." Journal of Advanced Research in Fluid Mechanics and Thermal Sciences 74, no. 1 (2020): 35-44. https://doi.org/10.37934/arfmts.74.1.3544

[11] Khanjari, Y., F. Pourfayaz, and A. B. Kasaeian. "Numerical investigation on using of nanofluid in a water-cooled photovoltaic thermal system." Energy Conversion and Management 122 (2016): $263-278$. https://doi.org/10.1016/i.enconman.2016.05.083

[12] Hosseinzadeh, Mohammad, Ali Salari, Mohammad Sardarabadi, and Mohammad Passandideh-Fard. "Optimization and parametric analysis of a nanofluid based photovoltaic thermal system: 3D numerical model with experimental validation." Energy Conversion and Management $160 \quad$ (2018): https://doi.org/10.1016/i.enconman.2018.01.006

[13] Khelifa, A., K. Touafek, H. Ben Moussa, and I. Tabet. "Modeling and detailed study of hybrid photovoltaic thermal (PV/T) solar collector." Solar Energy 135 (2016): 169-176. https://doi.org/10.1016/j.solener.2016.05.048

[14] Maadi, Seyed Reza, Meysam Khatibi, Ehsan Ebrahimnia-Bajestan, and David Wood. "Coupled thermal-optical numerical modeling of PV/T module-Combining CFD approach and two-band radiation DO model." Energy Conversion and Management 198 (2019): 111781. https://doi.org/10.1016/i.enconman.2019.111781

[15] Abdullah, Amira Lateef, S. Misha, N. Tamaldin, M. A. M. Rosli, and F. A. Sachit. "Theoretical study and indoor experimental validation of performance of the new photovoltaic thermal solar collector (PVT) based water system." Case Studies in Thermal Engineering 18 (2020): 100595. https://doi.org/10.1016/i.csite.2020.100595

[16] Filipović, Petar, Damir Dović, Borjan Ranilović, and Ivan Horvat. "Numerical and experimental approach for evaluation of thermal performances of a polymer solar collector." Renewable and Sustainable Energy Reviews 112 
(2019): 127-139. https://doi.org/10.1016/j.rser.2019.05.023

[17] Hussain, M. Imtiaz, Jin-Hee Kim, and Jun-Tae Kim. "Nanofluid-powered dual-fluid photovoltaic/thermal (pv/t) system: Comparative numerical study." Energies 12, no. 5 (2019): 775. https://doi.org/10.3390/en12050775

[18] Khanjari, Y., A. B. Kasaeian, and F. Pourfayaz. "Evaluating the environmental parameters affecting the performance of photovoltaic thermal system using nanofluid." Applied Thermal Engineering 115 (2017): $178-187$. https://doi.org/10.1016/i.applthermaleng.2016.12.104

[19] Misha, S., Amira Lateef Abdullah, N. Tamaldin, M. A. M. Rosli, and F. A. Sachit. "Simulation CFD and experimental investigation of PVT water system under natural Malaysian weather conditions." Energy Reports (2019). https://doi.org/10.1016/i.egyr.2019.11.162

[20] Gunjo, Dawit Gudeta, Pinakeswar Mahanta, and Puthuveettil Sreedharan Robi. "Exergy and energy analysis of a novel type solar collector under steady state condition: Experimental and CFD analysis." Renewable Energy 114 (2017): 655-669. https://doi.org/10.1016/i.renene.2017.07.072 